\title{
Too Many Cooks Spoil the Broth: Infobesity in Multicultural Firms During Covid-19
}

\author{
Ankur Jaiswal \\ Indian School of Business \\ ankur_jaiswal@isb.edu
}

\author{
Ojaswi Malik \\ The University of Hong Kong \\ ojaswim@connect.hku.hk \\ Abhishek Kathuria \\ Indian School of Business \\ abhishek_kathuria@isb.edu
}

\author{
Prasanna Karhade \\ University of Hawai'i at Mānoa \\ karhade@hawaii.edu
}

\begin{abstract}
Globalized firms maintain a presence across multiple countries encompassing multiple cultures. Cross-border, multicultural firms can leverage digital technologies to harness diverse information spread across the organization to generate insights and innovation. Conversely, digital technologies can cause organizations to suffer from infobesity. We examine this dialectic tension in the context of the Covid-19 pandemic. We theorize that multicultural firms exhibited better performance, assessed through market measures, during the onset of the pandemic. We further maintain that the use of digital technologies to generate insights from data has a negative effect on the relationship between multiculturism and firm performance due to infobesity. Analysis of Fortune 500 firms, having 56,587 subsidiaries present in 179 distinct countries, demonstrates that multicultural firms witnessed relatively superior stock market returns during the first quarter of 2020. We make significant contributions to information systems and crosscultural research and to broader inter-disciplinary management research.
\end{abstract}

\section{Introduction}

Multicultural firms, which are organizations spread across culturally different countries across the globe, are commonplace given the globalized nature of supply chains and operations. As each country possesses its own unique culture, organizations present in multiple countries encompass multiple diverse cultures. Research shows that cross-border, multicultural firms can leverage digital technologies to harness diverse information spread across the organization to generate insights and innovation [1]. In contrast, recent research has also shown that digital technologies can cause organizations to suffer from information overload or infobesity [2,3]. Infobesity is a condition characterized by information overload whereby firms collect more information than they need or more information than they can efficiently use, which can overwhelm the processing capabilities of an organization and its decision makers [4].

This study is situated within a recent and ongoing phenomenon - the Covid-19 pandemic. We study the effect of digital technologies on the performance of multicultural firms within this context of a large-scale, abrupt, and unexpected disruption that embodies simultaneous demand and supply shocks. Our primary thesis is that though multicultural firms exhibit better performance during the Covid-19 pandemic, digital technologies have a detrimental effect on their performance. Our reasoning behind this thesis is as follows. Multicultural firms exhibit superior performance during the pandemic by virtue of the diverse and distributed base of cultural knowledge, norms, practices, and perspectives that are present within the organization. Such knowledge, norms, practices, and perspectives can lend themselves to the quick and rapid development of new ways of doing business necessary to survive and thrive in the face of the pandemic. However, digital technologies used to store, process, and derive insights from this knowledge (which we term Digital Insights Capacity) generate infobesity, such that multicultural firms are unable to take quick and effective decisions required in this context. The knowledge-based view of the firm forms the theoretical edifice of our research model.

However, empirical examination of this theory faces two challenges. First, the pandemic is a mutating and evolving phenomenon, constituting an ongoing health shock, interspersed by intermittent economic shocks. The research design must ensure that health effects and economic effects of Covid-19 are not 
conflated. Consequently, to address this issue, we test our theory by examining the performance of U.S. headquartered Fortune 500 firms during the first quarter of 2020. This quarter witnessed an economic shock, constituting demand and supply side shocks, which resulted in a stock market crash and recovery. The health impacts of the pandemic were minimal during this quarter and only surfaced in subsequent quarters of 2020.

Second, firm performance is haunted by the ghosts of the past. Ergo, it is a function of decisions taken in the past. It is also a function of decisions taken during the present. Accordingly, accounting metrics of performance are problematic as they reflect decisions taken in the current as well as previous quarters. For example, firms with low levels of inventory in quarter 4 of 2019 would experience better accounting measures of performance relative to other firms during quarter 1 of 2020. Also, accounting metrics of performance are slow in incorporating information and thus, good decisions taken by firms during the first quarter of 2020 may only reflect subsequently. Ergo, our research design constitutes the use of marketbased metrics of performance as capital markets are efficient, forward-looking, and incorporate information quickly, while discounting past decisions [5].

We analyze Fortune 500 firms with 56,587 subsidiaries present in 179 distinct countries. We find strong and conclusive evidence that multicultural firms demonstrate better firm performance during the Covid-19 pandemic as evidenced by increased mean abnormal returns in the cross-section during the first quarter of 2020. However, use of digital technologies to generate insights from data reduces the performance effects of multiculturism, thereby affirming our key notion that too many cooks spoil the broth.

\section{Related Literature}

Globalized supply chains and operations require firms to maintain a presence across multiple countries. Such global operations face several challenges that have been highlighted by international business literature. These include institutional differences, tax regime differences, political differences, geographical distances, and most critically, cultural differences [1]. The presence of firms in other countries is in the form of temporally or geographically distant employees, who are situated within the cultural environment of their host nation. Thus, globally distributed employees embody multiple cultures.

Multicultural firms operate across countries with different cultures. These firms reflect the cultural differences between countries where the firm operates on the dimensions of power distance, individualism, uncertainty avoidance, and masculinity [6, 7]. Greater differences in these values between countries imply higher diversity of culture [8], and thus higher multiculturism. Hofstede's [9] conceptualization of national culture is the best established and has been used extensively in prior literature $[1,10,11]$.

Infobesity research has focused on the individual level of analysis. However, the information processing view of the firm has called for extending this inquiry to the organizational level [12]. This view perceives organizations as information processing systems and highlights how the imbalance between the firms' information processing capabilities and the information load encountered by them can create infobesity or underload [13]. Infobesity is a condition faced by firms where they collect more information than they need or more than they can efficiently use and hence the collected information becomes a source of information overload.

The firms' employees, decision makers and knowledge workers rely on frequent interactions with multiple sources of information in numerous intrafirm and inter-firm activities to allow for experimentation, innovations $[14,15]$ and decisions. However, as firms' information environment becomes increasingly complex with excess data, this infobesity in organizations creates technostress and affects the attention retention capacity of individuals [16-18] which leads to further negative reactions such as frustration and dissatisfaction $[19,20]$. This can hinder individuals' productivity and performance which can have detrimental consequences on their decisionmaking and innovation activities [13, 21]. Consequently, the organizations are unable to quickly and effectively take decisions required in this context of information overload [22, 23]. Their performance diminishes owing to detrimental effect of infobesity.

Prior research has established that a firm's technology use and digital resource endowments enable a firm to transform excess information into business insights [24, 25] and thus, make it valueadding [26-29]. Ergo, IT-enabled capabilities related to information storage, management, processing, and analysis have a positive impact on the organizations' performance such as productivity enhancement, profitability improvement, cost reduction, etc. [30-35]. However, the use of these technologies also exposes the firm to an abundance of information, which may prove deleterious under situations that require quick and efficient decision making [36]. 


\section{Theoretical Development}

Performance during the Covid-19 pandemic requires firms to sense and respond to disruptions in both supply and demand through efficient and effective decision making at speed [37-39]. Prior research in the decision sciences and information systems areas has investigated the role of various incentive-based theories, such as transaction cost economics, in enhancing efficiencies of firms and their supply chains in responding to disruptions [40, 41]. In contrast, we articulate theoretical explanations for the performance of multicultural firms during the Covid19 pandemic and how digital technology derived infobesity negatively moderates this relationship based upon the Knowledge Based View [40].

First, high multiculturism within a firm can offer superior opportunities for arbitrage. Knowledge of cultural practices and norms provides firms opportunities to explore and exploit variance across countries and thus arbitrage economic differences across countries [42, 43]. These opportunities may be leveraged to create new ways of doing business during the Covid-19 pandemic. Second, multicultural firms benefit from learning opportunities across dissimilar cultures with unique competencies and perspectives $[44,45]$. Potential combinations of these competencies and perspectives can result in an abundant and wide span of ideas, viewpoints, and practices that can be generalized across new contexts arising from the Covid-19 pandemic [46]. In line, with these arguments, we posit our first hypothesis:

\section{Hypothesis 1: Multicultural firms exhibit superior firm performance during the Covid-19 pandemic.}

Digital technologies, such as data storage systems and business intelligence systems, are used to store, process, and derive insights from knowledge [35]. We term such use of digital technologies as Digital Insights Capacity (DIC).

Deriving arbitrage and combinatorial advantages requires time to analyze, compare, and evaluate different options. Although Digital Insights Capacity allows firms to uncover obscure and weak signals of knowledge, which can result in exploratory innovations during regular times [1], these increase combinatorial complexity and redundancy of information. During a pandemic situation, firms are required to take quick and effective decisions due to paucity of time. Digital Insights Capacity results in infobesity as it generates more options, which further increases the time requirements of analyzing, comparing, and evaluating alternatives [47]. Thus, Digital Insights Capacity reduces the effect of multiculturism on firm performance. These arguments lead us to our second hypothesis:

Hypothesis 2: Digital Insights Capacity weakens the effect of multiculturalism on firm performance during the Covid-19 pandemic.

\section{Methods}

\subsection{Methodology}

Our research model posits that multicultural firms receive abnormal rewards during the Covid-19 pandemic. Though accounting based measures of performance are used extensively in prior literature [36, 48-51], these are inadequate for our research design. Instead, we use an event study methodology to estimate the stock market performance at the onset of the Covid-19 event $[52,53]$. This methodology is used to estimate abnormal returns associated with specific events after controlling for market wide factors that influence stock prices [54]. Abnormal returns reflect the stock price changes associated with an event, where an abnormal return is defined as the difference between the "return while the event is happening" and the "return if the event had not happened".

Here, the "return while the event is happening" is the actual return on the market, which is both observable and measurable. However, the "return if the event had not happened" is neither observable, nor measurable; instead, it must be estimated. The portion of the actual return that can be attributed to the event constitutes the abnormal return, which in turn reflect the stock market's perception of the decisions taken by the firm during the event. This methodology is based on the efficient market hypothesis, which maintains that the shareholder value effects of an event are quickly reflected in the stock price. Therefore, by estimating abnormal returns, we are estimating the difference between two realities - the returns in a reality where the pandemic happened (which is our reality), and an alternate reality wherein the pandemic did not happen.

We use the market model to estimate abnormal market returns $[55,56]$. The market model assumes that stock return and market return are related over a given period through the relationship:

$$
R_{i t}=\alpha_{i}+\beta_{i} R_{m t}+\varepsilon_{i t}
$$

where $R_{i t}$ is the return of stock $i$ in time $t, R_{m t}$ is the market return in time $t$, and $\alpha_{i}$ is the intercept of the relationship for stock $i . \beta_{i}$ is the systematic risk (or beta) of stock $i$, which captures the sensitivity of stock 
$i$ 's return to the market return. $\varepsilon_{i t}$ is the error term for stock $i$ in time $t$.

The movement of the stock market is represented by $\beta_{i} R_{m t}$ and accounts for a portion of the return of stock $i$. $\varepsilon_{i t}$ represents the portion of the return of the stock that is unexplained by market movements. We use ordinary least squares regression over a period of 2017 to 2019 to estimate $\widehat{\alpha}_{l}$ and $\widehat{\beta}_{l}$. Abnormal return is estimated for the first quarter of 2020.

We employ a cross-section regression specification for our analysis to assess our hypothesized model. The cross-sectional regression of firms' Firm Performance is as specified in equation (2) below:

$$
\begin{aligned}
& \text { Firm Performance }_{i} \\
& \qquad \begin{aligned}
& \beta_{0}+\beta_{1} \text { Multiculture }_{i} \\
& +\beta_{2} \text { DIC } \\
& +\beta_{3} \text { Multiculture }_{i} * D I C_{i} \\
& +\beta_{4} X_{i}+\beta_{5} \varphi_{i}+\epsilon_{i}
\end{aligned}
\end{aligned}
$$

Here, $\beta_{1}$ is the parameter which captures the direct effect of multiculturism of firm $i$ in 2018 on its Firm Performance, $\beta_{2}$ is the parameter which captures the direct effect of DIC of firm $i$ in 2018 on its Firm Performance, and $\beta_{3}$ is the parameter of interest that captures the interaction effect of multiculturism and DIC of firm $i$ in 2018 on its Firm Performance, during the first quarter of 2020. $X$ is an array of time variant firm-level controls for firm $i$ in 2019 and $\varphi$ accounts for industry fixed effects based on the Fama-French industry of firm $i$. The advantage of this regression specification is that it is not associated with a specific shock date.

\subsection{Data}

We use multiple archival data sources to collate data for our sample of Fortune 500 firms.

First, we obtain the locations of each firm's significant subsidiaries from a proprietary database. Such data have been used extensively in prior studies involving locations of subsidiaries and culture e.g., [1, 57]. This data together with Hofstede cultural dimensions scores is used to create the first independent variable of our study. Second, we obtain a firm's Data Insights Capacity from the CI database which is populated through a survey of IT usage by nearly 17,000 sites across the U.S. These data have been widely used in prior research on the impacts of IT [58-61]. Third, we obtain data on stock returns from the Center for Research in Security Prices database. Data from the first quarter of 2020 is utilized to create the dependent variable of our study as it captures the "return while the event is happening". Data on stock returns for all quarters of 2017 to 2019 is used in the market model to estimate abnormal market returns, and thus the "returns if the event had not happened". Finally, we retrieve quarterly accounting data for quarter four of 2019 from the Compustat database to create the array of control variables for our regression specification.

After matching all datasets, our final sample consists of observations for 363 distinct firms. These firms collectively have 56,587 subsidiaries present across 179 distinct countries. Table 1 reports the characteristics of the firms in the sample. This table captures the distribution of the firms across industries, their size (in terms of revenue in million US dollars), number of subsidiaries, and spread across number of

\begin{tabular}{|c|c|c|}
\hline Characteristic & Category & Percentage \\
\hline \multicolumn{3}{|l|}{ Industry } \\
\hline & Consumer Nondurables & 6.01 \\
\hline & Consumer Durables & 4.10 \\
\hline & Manufacturing & 15.57 \\
\hline & Energy & 6.28 \\
\hline & Hi-Tech & 12.02 \\
\hline & Telecom & 2.19 \\
\hline & Shops \& Services & 15.85 \\
\hline & Healthcare & 6.83 \\
\hline & Utilities & 3.55 \\
\hline & Others & 27.60 \\
\hline \multicolumn{3}{|c|}{ Size (in million US dollars) } \\
\hline & Less than 5000 & 7.00 \\
\hline & 5001-10000 & 30.70 \\
\hline & $10001-25000$ & 38.37 \\
\hline & $25001-50000$ & 11.29 \\
\hline & 50001-100000 & 6.09 \\
\hline & More than 100000 & 6.55 \\
\hline \multicolumn{3}{|c|}{ Number of Subsidiaries } \\
\hline & Less than 10 & 0.32 \\
\hline & $11-25$ & 1.59 \\
\hline & 26-100 & 12.00 \\
\hline & $101-250$ & 27.78 \\
\hline & $251-500$ & 27.37 \\
\hline & $501-750$ & 12.63 \\
\hline & More than 750 & 18.32 \\
\hline \multicolumn{3}{|c|}{ Spread across Number of Countries } \\
\hline & Less than 10 & 53.61 \\
\hline & $11-25$ & 17.95 \\
\hline & $26-50$ & 20.28 \\
\hline & More than 50 & 8.16 \\
\hline
\end{tabular}
countries. The stocks corresponding to the firms in the sample, contain a mix of both, growth stocks and value stocks.

Table 1. Sample Firm Characteristics 


\subsection{Variables}

4.3.1. Independent Variables Our first independent variable captures the extent to which a firm is spread across culturally different countries across the globe $[1,62]$. As described in the theory development section, a firm's employees embody the different cultures it is constituted of. These employees are employed by the firm's subsidiaries that are present across the globe. Therefore, we use firms' subsidiaries to measure Multiculturism. This research design is aligned with prior literature that notes that subsidiaries "reflect the values, norms, and locally accepted practices of the societies in which they operate" ([63], p. 345).

We first calculate the cultural distance for each subsidiary pair [8]. This well-established measure of cultural distance $[64,65]$ is based on deviation of the two countries along four of Hofstede's cultural dimensions (i.e., power distance, individualism, masculinity, uncertainty avoidance, [66]). We then calculate Multiculturism of the firm as the average of cultural distances for all possible pairs of subsidiaries of the firm [1,67]. This independent variable is estimated at the end of 2018. A one-year lag in the measurement accounts for information assimilation and processing by the firm and the market, ensuring that stock market reactions are to Multiculturism from before the pandemic.

Our second variable is the firm's Digital Insights Capacity, which is obtained from Harte Hanks. Harte Hanks provides information on implementation of various digital technologies at the firm-level. In line prior literature $[1,51]$, the summative score of business intelligence and data storage digital technologies possessed by the firm at the end of 2018 constitutes the measure of Digital Insights Capacity.

4.3.2. Dependent Variables Quarterly Abnormal Return of a stock is our dependent variable and thus, measure of firm performance during the first quarter of 2020. It is estimated as the difference between the logarithm of the stock's gross quarterly return and the CAPM beta times the logarithm of the market's gross quarterly return over the first quarter of 2020. The CAPM beta is estimated using returns from 2017 and 2019, and the S\&P 500 as the market index, using the market model as specified.

4.3.3. Control Variables We include an extensive set of control variables in our regression specification. Tobin's $Q$ is a forward-looking measure of firm performance and may influence stock returns. Firm Size accounts for scale effects. The Cash holdings of a firm can affect its attractiveness to investors. Leverage accounts for the ability for the firm to raise funds and hence influences its stock price. Firms with high Return on Equity (ROE) are more attractive. We control for Advertising Expenditures as this reflects opportunities for future customer growth. We also control Historical Volatility. Finally, Dividend and Liquidity increase attractiveness of a stock. All controls are measured in 2019 US dollars.

The measures are summarized in Table 2. We observe that the mean value of Multiculturism is 39.295, with standard deviation of 17.347. As the scale ranges from minimum 1.050 to maximum 75.824 , firms in the sample are widely dispersed and not uniformly clustered around the mean with respect to Multiculturism. The mean value of Digital Insights Capacity $(D I C)$ is 0.727 with low standard deviation, suggesting that firms' $D I C$ is clustered around the mean. Quarterly Abnormal Returns has a mean of negative $25.096 \%$, implying that on average all the firms in the sample suffered highly unexpected negative returns during the first quarter of 2020 . However, these negative returns were not uniform across all firms as suggested by the high standard deviation. Similarly, the mean of Total Quarterly Volatility and Idiosyncratic Volatility is high and greater than zero, with standard deviation close to one. This suggests that firms experienced high volatility in stock prices during the first quarter of 2020 .

Table 2. Summary Statistics

\begin{tabular}{|lrr|}
\hline Variable & Mean & Std. Dev. \\
\hline Multiculturism & 39.295 & 17.347 \\
Digital Insights Capacity & 0.727 & 0.499 \\
\hline Quarterly Abnormal Returns & -25.096 & 31.373 \\
\hline Tobin's Q & 1.894 & 1.188 \\
Firm Size & 9.635 & 0.966 \\
Cash & 0.088 & 0.096 \\
Leverage & 0.337 & 0.179 \\
Return on Equity (ROE) & 0.126 & 0.642 \\
Advertising & 0.008 & 0.019 \\
Historical Volatility & 1.791 & 0.765 \\
Dividend & 2.200 & 2.093 \\
\hline
\end{tabular}

\section{Results}

\subsection{Main Analysis}

We assess our hypothesis by utilizing a hierarchical regression specification. As our data does not have any specific properties (e.g., count or binary), we use ordinary least squares (OLS) specifications. According to the Breusch-Pagan test for heteroskedasticity, we reject the null hypothesis that the errors are homoscedastic in all the models. Thus, although the OLS estimators are unbiased and 
consistent, they are not efficient, and the estimated standard errors are incorrect. Therefore, we correct for this issue by using heteroscedastic robust standard errors across all our regression specifications. Furthermore, there is no issue of multicollinearity in any of the models, as assessed by Variance Inflationary Factor, which are all less than 3. The variables used in all the regression models are winsorized at $1 \%$ in each tail. In addition, regression constants are omitted for brevity, and standardized regression coefficients and robust standard errors are reported in all results tables presented hereafter.

Table 3: Analysis of Direct Effects of Multiculturism on Firm Performance

\begin{tabular}{|c|c|c|c|}
\hline VARIABLES & $\begin{array}{c}\text { (1) } \\
\text { Firm } \\
\text { Performance }\end{array}$ & $\begin{array}{c}\text { (2) } \\
\text { Firm } \\
\text { Performance } \\
\end{array}$ & $\begin{array}{c}\text { (3) } \\
\text { Firm } \\
\text { Performance } \\
\end{array}$ \\
\hline Multiculturism & $\begin{array}{c}0.186^{* * * *} \\
(0.114)\end{array}$ & $\begin{array}{c}0.097^{* *} \\
(0.098)\end{array}$ & $\begin{array}{l}0.084 * \\
(0.095)\end{array}$ \\
\hline Tobin's Q & & $\begin{array}{c}0.258 * * * \\
(1.386)\end{array}$ & $\begin{array}{c}0.261 * * * \\
(1.459)\end{array}$ \\
\hline Size & & $\begin{array}{c}0.167 * * * \\
(1.591)\end{array}$ & $\begin{array}{c}0.131 * * * \\
(1.516)\end{array}$ \\
\hline Cash & & $\begin{array}{c}0.122 * * \\
(16.588)\end{array}$ & $\begin{array}{c}0.082 * \\
(15.956)\end{array}$ \\
\hline Leverage & & $\begin{array}{c}-0.028 \\
(8.751)\end{array}$ & $\begin{array}{c}-0.049 \\
(8.752)\end{array}$ \\
\hline ROE & & $\begin{array}{c}0.018 \\
(1.870)\end{array}$ & $\begin{array}{c}0.007 \\
(1.900)\end{array}$ \\
\hline Advertising & & $\begin{array}{c}-0.070^{*} \\
(78.654)\end{array}$ & $\begin{array}{l}-0.072^{*} \\
(86.792)\end{array}$ \\
\hline Hist. Volatility & & $\begin{array}{c}-0.114 * \\
(3.583)\end{array}$ & $\begin{array}{c}-0.124 * \\
(3.577)\end{array}$ \\
\hline Dividend & & $\begin{array}{c}-0.214 * * * \\
(1.017)\end{array}$ & $\begin{array}{c}-0.166 * * * \\
(0.966)\end{array}$ \\
\hline Observations & 366 & 363 & 363 \\
\hline R-squared & 0.035 & 0.262 & 0.310 \\
\hline Industry FE & No & No & Yes \\
\hline $\mathrm{F}$ & $9.053 * * *$ & $13.24 * * *$ & $12.17 * * *$ \\
\hline F change & - & $13.476^{* * *}$ & $6.017 * * *$ \\
\hline
\end{tabular}

Table 3 presents the results of the analysis of direct effects of Multiculturism, using cross-sectional regressions of firms' Quarterly Abnormal Returns. Column 1 presents the results when only Multiculturism is used as the explanatory variable. In Column 2, in addition to Multiculturism, we add a set of control variables that are known to affect firm performance. Lastly in Column 3 , in addition to the explanatory variables used in column 2, we add dummy variables that capture industry-level, time invariant fixed effects (Industry FE). This is denoted by 'Yes' in column 3 and 'No' in column 1 and 2, corresponding to the row labeled 'Industry FE'. The regression coefficients for these Industry $\mathrm{FE}$ are omitted for brevity. In Column 1 we find the direct effect of Multiculturism is 0.186 ( $\mathrm{p}<0.01$ ), excluding controls and industry fixed effects. In Column 2, including firm controls but excluding industry fixed effects, we find that the coefficient of Multiculturism is $0.097(\mathrm{p}<0.05)$, while after including both firm controls and industry fixed effects in Column 3 , the direct effect of Multiculturism is $0.084(\mathrm{p}<0.1)$. This supports hypothesis 1 .

Though we do not hypothesize this relationship, we examine the direct effect of DIC in isolation. Table 4 presents the results of the analysis of direct effects of DIC, using cross-sectional regressions of firms' Quarterly Abnormal Returns. Column 1 presents the results when only $D I C$ is used as the only explanatory variable. In Column 2, we augment DIC with a set of control variables that are known to affect firm performance while in Column 3, we further include industry-level, time invariant fixed effects. In Column 1 we find the direct effect of DIC is 0.089 ( $p<0.05)$. In Column 2, including firm controls but excluding industry fixed effects, we find that the coefficient of $D I C$ is $0.064(\mathrm{p}<0.1)$, while after including both firm controls and industry fixed effects in Column 3 , the direct effect of $D I C$ is $0.068(\mathrm{p}<0.1)$.

Table 4: Analysis of Direct Effects of Data Insights Capacity on Firm Performance

\begin{tabular}{|c|c|c|c|}
\hline VARIABLES & $\begin{array}{c}\text { (1) } \\
\text { Firm } \\
\text { Performance } \\
\end{array}$ & $\begin{array}{c}\text { (2) } \\
\text { Firm } \\
\text { Performance } \\
\end{array}$ & $\begin{array}{c}(3) \\
\text { Firm } \\
\text { Performance }\end{array}$ \\
\hline DIC & $\begin{array}{c}0.089 * * \\
(3.410)\end{array}$ & $\begin{array}{l}0.064 * \\
(2.852)\end{array}$ & $\begin{array}{l}0.068 * \\
(2.901)\end{array}$ \\
\hline Tobin's Q & & $\begin{array}{c}0.269 * * * \\
(1.216)\end{array}$ & $\begin{array}{c}0.261 * * * \\
(1.275)\end{array}$ \\
\hline Size & & $\begin{array}{c}0.185 * * * \\
(1.406)\end{array}$ & $\begin{array}{c}0.158 \text { *** } \\
(1.403)\end{array}$ \\
\hline Cash & & $\begin{array}{l}0.095^{* *} \\
(15.644)\end{array}$ & $\begin{array}{c}0.072 * \\
(15.397)\end{array}$ \\
\hline Leverage & & $\begin{array}{c}-0.032 \\
(7.620)\end{array}$ & $\begin{array}{l}-0.055 \\
(7.734)\end{array}$ \\
\hline ROE & & $\begin{array}{l}-0.005 \\
(1.759)\end{array}$ & $\begin{array}{l}-0.017 \\
(1.741)\end{array}$ \\
\hline Advertising & & $\begin{array}{l}-0.078^{*} \\
(81.059)\end{array}$ & $\begin{array}{l}-0.080 * \\
(87.019)\end{array}$ \\
\hline Hist. Volatility & & $\begin{array}{l}-0.069 \\
(3.044)\end{array}$ & $\begin{array}{c}-0.086 \\
(3.089)\end{array}$ \\
\hline Dividend & & $\begin{array}{c}-0.221 * * * \\
(0.861)\end{array}$ & $\begin{array}{c}-0.190 * * * \\
(0.870)\end{array}$ \\
\hline Observations & 443 & 440 & 440 \\
\hline R-squared & 0.008 & 0.236 & 0.265 \\
\hline Industry FE & No & No & Yes \\
\hline $\mathrm{F}$ & $2.721 * * *$ & $15.08 * * *$ & $12.90 * * *$ \\
\hline F change & & $31.789 * * *$ & $8.069 * * *$ \\
\hline
\end{tabular}


Table 5 presents the results of the analysis of the interaction effects of Multiculturism and DIC while retaining the main effects of both the variables, using cross-sectional regressions of firms' Quarterly Abnormal Returns. Column 1 includes Multiculturism and DIC along with set of control variables that are known to affect firm performance. In Column 2, we include the interaction effect of DIC on Multiculturism. Furthermore, this interaction effect is tested using the $\mathrm{F}$ test for change in R-square, the significance of which is also reported. In Column 3, we include industry-level, time invariant fixed effects.

Table 5: Interaction Effects of Multiculturism and Data Insights Capacity on Firm Performance

\begin{tabular}{|c|c|c|c|}
\hline VARIABLES & $\begin{array}{c}\text { (1) } \\
\text { Firm Perf. }\end{array}$ & $\begin{array}{c}\text { (2) } \\
\text { Firm Perf. }\end{array}$ & $\begin{array}{c}\text { (3) } \\
\text { Firm Perf. }\end{array}$ \\
\hline Multiculturism & $\begin{array}{l}0.089^{*} \\
(0.100)\end{array}$ & $\begin{array}{c}0.220 * * * \\
(0.152)\end{array}$ & $\begin{array}{c}0.180^{* *} \\
(0.149)\end{array}$ \\
\hline DIC & $\begin{array}{c}0.052 \\
(3.459)\end{array}$ & $\begin{array}{c}0.273 * * \\
(7.992)\end{array}$ & $\begin{array}{c}0.253 * * \\
(7.904)\end{array}$ \\
\hline Multiculturism*DIC & & $\begin{array}{c}-0.290 * * \\
(0.184)\end{array}$ & $\begin{array}{c}-0.235^{* *} \\
(0.181)\end{array}$ \\
\hline Tobin's Q & $\begin{array}{c}0.266 * * * \\
(1.394)\end{array}$ & $\begin{array}{c}0.257 * * * \\
(1.380)\end{array}$ & $\begin{array}{c}0.266 * * * \\
(1.450)\end{array}$ \\
\hline Size & $\begin{array}{c}0.163 * * * \\
(1.564)\end{array}$ & $\begin{array}{c}0.157 * * * \\
(1.529)\end{array}$ & $\begin{array}{c}0.120 * * * \\
(1.466)\end{array}$ \\
\hline Cash & $\begin{array}{l}0.122 * * \\
(16.744)\end{array}$ & $\begin{array}{l}0.121^{* *} \\
(16.498)\end{array}$ & $\begin{array}{c}0.081 * \\
(15.954)\end{array}$ \\
\hline Leverage & $\begin{array}{l}-0.033 \\
(8.669)\end{array}$ & $\begin{array}{l}-0.030 \\
(8.681)\end{array}$ & $\begin{array}{l}-0.052 \\
(8.707)\end{array}$ \\
\hline ROE & $\begin{array}{c}0.012 \\
(1.816)\end{array}$ & $\begin{array}{c}0.020 \\
(1.875)\end{array}$ & $\begin{array}{c}0.006 \\
(1.887)\end{array}$ \\
\hline Advertising & $\begin{array}{l}-0.066^{*} \\
(77.691)\end{array}$ & $\begin{array}{c}-0.057 \\
(77.699)\end{array}$ & $\begin{array}{c}-0.061 \\
(84.941)\end{array}$ \\
\hline Hist. Volatility & $\begin{array}{c}-0.103 \\
(3.678)\end{array}$ & $\begin{array}{c}-0.108 \\
(3.551)\end{array}$ & $\begin{array}{l}-0.113^{*} \\
(3.572)\end{array}$ \\
\hline Dividend & $\begin{array}{c}-0.214 * * * \\
(1.013)\end{array}$ & $\begin{array}{c}-0.214 * * * \\
(1.004)\end{array}$ & $\begin{array}{c}-0.167 * * * \\
(0.950)\end{array}$ \\
\hline Observations & 363 & 363 & 363 \\
\hline R-squared & 0.264 & 0.275 & 0.321 \\
\hline Industry FE & No & No & Yes \\
\hline $\mathrm{F}$ & $12.07 * * *$ & $11.51 * * *$ & $10.93 * * *$ \\
\hline F change & & $5.137 * *$ & $5.918 * * *$ \\
\hline
\end{tabular}

In Column 1 we find the direct effect of Multiculturism is $0.089(\mathrm{p}<0.1)$ and DIC is 0.052 $(\mathrm{p}<0.1)$. Both the direct effects are in the same direction but only Multiculturism is significant. When we include the interaction between Multiculturism and $D I C$ in Column 2, we find that the coefficient of Multiculturism*DIC is $-0.290(\mathrm{p}<0.05)$. In Column 3, when we include the industry fixed effects, we find that the coefficient of Multiculturism*DIC is -0.235 $(p<0.05)$ and simultaneously the result of direct effects also retained and significant.

We validate our second hypothesis through the results presented in Table 5; column 3, where the interaction effect of DIC on Multiculturism ( $\mathrm{p}<0.05$ ) is significant and in the hypothesized direction. The magnitude of the coefficient estimates suggests that, at the mean value of Multiculturism, one standard deviation increase in $D I C$, negatively moderates the direct effect of Multiculturism and is associated with lowering quarterly stock return by $7.37 \%(-0.235 \mathrm{x}$ 31.373) on average. This comprehensive analysis presents strong support for $\mathrm{H} 2$.

\subsection{Supplementary Analysis}

To supplement our main analysis of Quarterly Abnormal Returns, we further examine the interaction effect of Multiculturism and DIC on the volatility of stock returns during the quarter by repeating the crosssectional regressions for Total Volatility and Idiosyncratic Volatility, while retaining the main effects of both the variables. We do not report these results due to space constraints. The results suggest that firm with high Multiculturism have significantly reduced total stock return volatility and idiosyncratic stock return volatility during the first quarter of 2020 .

\section{Discussion and Conclusion}

Global supply chains and operations are a prerequisite to most commerce. There has been research regarding the advantages of such global presence. However, the issue of presence across multiple cultures has been usually portrayed as a disadvantage that must be overcome. This study proposes that global organizations have an advantage due to their multiculturalism. Specifically, we demonstrate that multicultural firms exhibit superior firm performance during the pandemic. Furthermore, while digital technologies lend greater effectiveness to multiculturism under regular circumstances, the Covid-19 pandemic requires firms to be quick and efficient in their decision making. We theorize that Digital Insights Capacity generates infobesity, which results in reducing (negatively moderating) the superior performance of multicultural firms during the pandemic. We find strong support for this hypothesis.

\subsection{Contributions}

Two contributions of our study are particularly salient. First, prior literature in IS has mostly focused on highlighting how IS enable firms to overcome the 
negative consequences of multiple cultures, often resulting in favorable outcomes such as exploratory innovation. Literature has also noted that benefits of IS for a firm are contingent upon the multinational nature, country of origin, and country of operation of the firm [68]. We introduce a nuance to this narrative, whereby we demonstrate that while multiculturism has a standalone positive impact on performance, IS have a negative consequence when used in multicultural firms during contexts such as the pandemic. Second, our paper joins the stream of research which makes substantial contributions to the theories of the firm by leveraging a knowledge-based view of multiculturism [69]. Though there have been notable advances to this stream of literature, it is still in a nascent stage. Thus, our study moves this work forward substantively.

\subsection{Limitations}

We acknowledge three limitations of our work. First, our empirical specification cannot fully control for time-varying factors, such as seasonal variations in demand, which may affect stock market performance of firms. Second, our study examines only the Covid19 pandemic. Future research can attempt to replicate and improve upon our findings in different contexts [e.g., 56, 70]. Finally, it is plausible that a firm that is more geographically diversified would also be more resilient to global crises. However, since our theory pertains to knowledge diversity, this relationship would be stronger if a firm is present in more dissimilar geographies, implying multiculturalism.

\subsection{Conclusions}

Effects of Multiculturism are reflected both in increased firm performance as measured by abnormal returns and in reduced volatility during the first quarter of 2020, while the effects on abnormal returns are negatively moderated by Digital Insights Capacity. These provide evidence to our theory that while firms with high multiculturism exhibit superior performance during the pandemic, digital technologies reduce their performance due to infobesity; thereby affirming the adage that too many cooks spoil the broth.

\section{References}

[1] T. J. V. Saldanha, A. Sahaym, S. Mithas, M. G. Andrade-Rojas, A. Kathuria, and H.-H. Lee, "Turning Liabilities of Global Operations into Assets: ITEnabled Social Integration Capacity and Exploratory Innovation," Information Systems Research, vol. 31, no. 2, pp. 361-382, 2020.
[2] P. P. Karhade and D. John Qi, "Innovation Outcomes of Digitally Enabled Collaborative Problemistic Search Capability," MIS Quarterly, vol. 45, no. 2, 2021.

[3] S. Choi and I. Ko, "Leveraging electronic collaboration to promote interorganizational learning," International Journal of Information Management, vol. 32, no. 6, pp. 550-559, 2012.

[4] K. M. Sutcliffe and K. E. Weick, "Information overload revisited," in The Oxford handbook of organizational decision making: Oxford University Press, 2009.

[5] A. S. Bharadwaj, S. G. Bharadwaj, and B. R. Konsynski, "Information Technology Effects on Firm Performance as Measured by Tobin's q," Management Science, vol. 45, no. 7, pp. 1008-1024, 1999.

[6] D. Shin, V. C. Hasse, and A. P. J. Schotter, "Multinational Enterprises within Cultural Space and Place: Integrating Cultural Distance and TightnessLooseness," Academy of Management Journal, vol. 60, no. 3, pp. 904-921, 2017.

[7] S. Beugelsdijk, T. Kostova, V. E. Kunst, E. Spadafora, and M. van Essen, "Cultural Distance and Firm Internationalization: A Meta-Analytical Review and Theoretical Implications," Journal of Management, vol. 44, no. 1, pp. 89-130, 2018.

[8] B. Kogut and H. Singh, "The effect of national culture on the choice of entry mode," Journal of International Business Studies, vol. 19, no. 3, pp. 411-432, 1988.

[9] G. Hofstede, "Culture and Organizations," International Studies of Management \& Organization, vol. 10, no. 4, pp. 15-41, 1980.

[10] A. Kathuria, T. Saldanha, J. Khuntia, M. G. Andrade Rojas, and H. Hah, "Strategic Intent, Contract Duration, and Performance: Evidence from Micro-Outsourcing," in International Conference on Information Systems, 2015.

[11] A. Kathuria, T. Saldanha, J. Khuntia, M. Andrade Rojas, S. Mithas, and H. Hah, "Inferring Supplier Quality in the Gig Economy: The Effectiveness of Signals in Freelance Job Markets," in Hawaii International Conference on System Sciences, 2021.

[12] P. Karhade, A. Kathuria, O. Malik, and B. Konsynski, "Digital Platforms and Infobesity: A Research Agenda," in The Role of e-Business during the Time of Grand Challenges. WeB 2020. Lecture Notes in Business Information Processing, A. Garimella, P. Karhade, A. Kathuria, X. Liu, J. Xu, and K. Zhao Eds. Cham: Springer 2021, pp. 67-74.

[13] M. Tarafdar, Q. Tu, and T. S. Ragu-Nathan, "Impact of Technostress on End-User Satisfaction and Performance," Journal of Management Information Systems, vol. 27, no. 3, pp. 303-334, 2010.

[14] M. Andrade Rojas, T. Saldanha, J. Khuntia, A. Kathuria, and W. F. Boh, "Overcoming Innovation Deficiencies in Mexico: Use of Open Innovation through IT and Closed Innovation through IT by Small and Medium Enterprises," in Hawaii International Conference on System Sciences, 2021, p. 617.

[15] T. Saldanha, A. Kathuria, J. Khuntia, B. Konsynski, and M. Rojas, "Leveraging Digitalization of Services for Performance: Evidence from the Credit Union 
Industry," in International Conference on Information Systems, 2017.

[16] H. A. Simon, K. W. Deutsch, and M. Shubik, "Designing organizations for an information-rich world," in Computers, communications, and the public interest, ed, 1971, pp. 37--72.

[17] M. Tarafdar, C. Maier, S. Laumer, and T. Weitzel, "Explaining the link between technostress and technology addiction for social networking sites: A study of distraction as a coping behavior," Information Systems Journal, vol. 30, no. 1, pp. 96-124, 2020.

[18] H. Pirkkalainen, M. Salo, M. Tarafdar, and M. Makkonen, "Deliberate or Instinctive? Proactive and Reactive Coping for Technostress," Journal of Management Information Systems, vol. 36, no. 4, pp. 1179-1212, 2019.

[19] P. Hemp, "Death by information overload," Harvard business review, vol. 87, no. 9, pp. 82-9, 121, Sep 2009.

[20] T. S. Ragu-Nathan, M. Tarafdar, B. S. Ragu-Nathan, and Q. Tu, "The Consequences of Technostress for End Users in Organizations: Conceptual Development and Empirical Validation," Information Systems Research, vol. 19, no. 4, pp. 417-433, 2008.

[21] T. W. Jackson and P. Farzaneh, "Theory-based model of factors affecting information overload," International Journal of Information Management, vol. 32, no. 6, pp. 523-532, 2012.

[22] P. P. Karhade and J. Q. Dong, "Information Technology Investment and Commercialized Innovation Performance: Dynamic Adjustment Costs and Curvilinear Impacts," MIS Quarterly, vol. 45, no. 3, pp. 1007-1024, 2021.

[23] P. Karhade, M. J. Shaw, and R. Subramanyam, "Patterns in information systems portfolio prioritization," Mis Quarterly, vol. 39, no. 2, pp. 413434, 2015.

[24] M. Andrade Rojas and A. Kathuria, "Competitive brokerage, information technology and internal resources," in International Conference on Information Systems, 2014.

[25] M. Andrade Rojas, A. Kathuria, and B. Konsynski, "Competitive Brokerage: How Information Management Capability and Collaboration Networks Act as Substitutes," Journal of Management Information Systems, vol. Forthcoming, 2021.

[26] A. Kathuria, T. Saldanha, J. Khuntia, and M. Rojas, "How Information Management Capability Affects Innovation Capability and Firm Performance under Turbulence: Evidence from India," in International Conference on Information Systems, 2016.

[27] T. Ramakrishnan, A. Kathuria, and J. Khuntia, "Business Analytics Capability and Supply Chain Management," Americas Conference on Information Systems, 2018.

[28] T. Ramakrishnan, J. Khuntia, A. Kathuria, and T. J. Saldanha, "Business intelligence capabilities," in Analytics and Data Science: Springer, 2018, pp. 15-27.

[29] H.-T. Wagner, D. Beimborn, and T. Weitzel, "How Social Capital Among Information Technology and Business Units Drives Operational Alignment and IT
Business Value," Journal of Management Information Systems, vol. 31, no. 1, pp. 241-272, 2014.

[30] J. Q. Dong, J. He, and P. Karhade, "The Penrose effect in resource investment for innovation: Evidence from information technology and human capital," European Conference on Information Systems Proceedings, 2013.

[31] J. Q. Dong, P. Karhade, A. Rai, and S. X. Xu, "Dynamic adjustment of information technology, corporate governance, and firm profitability," European Conference on Information Systems Proceedings, 2013.

[32] J. Q. Dong, P. Karhade, A. Rai, and S. X. Xu, "Information technology in innovation activity of the firm: Theory and synthesis," European Conference on Information Systems Proceedings, 2013.

[33] S. Mithas, N. Ramasubbu, and V. Sambamurthy, "How Information Management Capability Influences Firm Performance," MIS Quarterly, vol. 35, pp. 237-256, 2011.

[34] T. Ramakrishnan, A. Kathuria, and T. J. Saldanha, "Business Intelligence and Analytics (BI\&A) Capabilities in Healthcare," in Theory and Practice of Business Intelligence in Healthcare: IGI Global, 2020, pp. 1-17.

[35] T. Ramakrishnan, J. Khuntia, A. Kathuria, and T. J. Saldanha, "An Integrated Model of Business Intelligence \& Analytics Capabilities and Organizational Performance," Communications of the Association for Information Systems, vol. 46, no. 1, p. 31, 2020.

[36] J. Q. Dong, P. P. Karhade, A. Rai, and S. X. Xu, "How Firms Make Information Technology Investment Decisions: Toward a Behavioral Agency Theory," Journal of Management Information Systems, vol. 38, no. 1, pp. 29-58, 2021.

[37] O. Malik, P. Karhade, and A. Kathuria, "How Technology Use Drives Infobesity: An In-Depth Look at ERP Systems," in Pacific Asia Conference on Information Systems, 2021.

[38] S. Vijaykar and P. Karhade, "Remote Virtual Workplaces in the Pandemic: The Case of IT-enabled Service Leadership," in Pacific Asia Conference on Information Systems, 2021.

[39] S. Vijaykar, P. Karhade, and M. Gupta, "Work-FromHome vs. Work-At-Home: A Strategic Conundrum in the Digital Age," in Americas Conference on Information Systems, 2021.

[40] M. Ketokivi and J. T. Mahoney, "Transaction cost economics as a theory of supply chain efficiency," Production and Operations Management, vol. 29, no. 4, pp. 1011-1031, 2020.

[41] J. M. Stauffer and S. Kumar, "Impact of Incorporating Returns into Pre-Disaster Deployments for RapidOnset Predictable Disasters," Production and Operations Management, vol. 30, no. 2, 2021.

[42] P. Ghemawat, "Managing differences: The central challenge of global strategy," Harvard business review, vol. 85, no. 3, pp. 58-68, 140, 2007.

[43] J.-L. Arregle, T. L. Miller, M. A. Hitt, and P. W. Beamish, "How does regional institutional complexity 
affect MNE internationalization?," Journal of International Business Studies, vol. 47, no. 6, pp. 697 722, 2016.

[44] P. Morosini, S. Shane, and H. Singh, "National cultural distance and cross-border acquisition performance," Journal of international business studies, vol. 29, no. 1, pp. 137-158, 1998.

[45] J. V. Gray and B. Massimino, "The Effect of Language Differences and National Culture on Operational Process Compliance," Production and Operations Management, vol. 23, no. 6, pp. 1042-1056, 2014.

[46] T. H. Reus and B. T. Lamont, "The double-edged sword of cultural distance in international acquisitions," Journal of International Business Studies, vol. 40, no. 8, pp. 1298-1316, 2009.

[47] P. P. Karhade, M. J. Shaw, and R. Subramanyam, "Patterns in strategic IS planning decisions: An inductive approach," in Americas Conference on Information Systems, 2009, p. 397.

[48] A. Kathuria, J. Khuntia, P. Karhade, and X. Ning, "Don't Ever Take Sides with Anyone Against the Family: Family Ownership and Information Management," in Americas Conference on Information Systems, 2019.

[49] X. Ning, J. Khuntia, A. Kathuria, and P. Karhade, "Information Technology Investment, Environmental Hostility, and Firm Performance: The Roles of Family Ownership in an Emerging Economy," in Hawaii International Conference on System Sciences, 2020.

[50] X. Ning, J. Khuntia, A. Kathuria, and P. Karhade, "Ownership and Management Control Effects on IT Investments: A Study of Indian Family Firms," in International Conference on Information Systems, 2020.

[51] T. Saldanha, A. Kathuria, J. Khuntia, and B. Konsynski, "Ghosts in the Machine: How Marketing and Human Capital Investments Enhance Customer Growth when Innovative Services Leverage Self-Service Technologies," Information Systems Research, 2021.

[52] C. Flammer, "Does corporate social responsibility lead to superior financial performance? A regression discontinuity approach," Management Science, vol. 61, no. 11, pp. 2549-2568, 2015.

[53] S. Ramelli and A. F. Wagner, "Feverish Stock Price Reactions to COVID-19," The Review of Corporate Finance Studies, vol. 9, no. 3, pp. 622-655, 2020.

[54] S. J. Brown and J. B. Warner, "Using daily stock returns: The case of event studies," Journal of Financial Economics, vol. 14, no. 1, pp. 3-31, 1985.

[55] K. B. Hendricks and V. R. Singhal, "The effect of supply chain glitches on shareholder wealth," Journal of Operations Management, vol. 21, no. 5, 2003.

[56] K. B. Hendricks, B. W. Jacobs, and V. R. Singhal, "Stock Market Reaction to Supply Chain Disruptions from the 2011 Great East Japan Earthquake," Manufacturing \& Service Operations Management, vol. 22, no. 4, pp. 683-699, 2020.

[57] S. Mithas, J. Whitaker, and A. Tafti, "Information Technology, Revenues, and Profits: Exploring the Role of Foreign and Domestic Operations," Information Systems Research, vol. 28, no. 2, pp. 430-444, 2017.
[58] M. Pincus, F. Tian, P. Wellmeyer, and S. X. Xu, "Do Clients' Enterprise Systems Affect Audit Quality and Efficiency?," Contemporary Accounting Research, vol. 34, no. 4, pp. 1975-2021, 2017.

[59] S. Dewan and F. Ren, "Information Technology and Firm Boundaries: Impact on Firm Risk and Return Performance," Information Systems Research, vol. 22, no. 2, pp. 369-388, 2011.

[60] N. Jia, A. Rai, and S. X. Xu, "Reducing Capital Market Anomaly: The Role of Information Technology Using an Information Uncertainty Lens," Management Science, vol. 66, no. 2, pp. 979-1001, 2020.

[61] C. Forman, "The Corporate Digital Divide: Determinants of Internet Adoption," Management Science, vol. 51, no. 4, pp. 641-654, 2005.

[62] L. R. Gomez-Mejia, M. Makri, and M. L. Kintana, "Diversification Decisions in Family-Controlled Firms," Journal of Management Studies, vol. 47, no. 2, pp. 223-252, 2010.

[63] P. M. Rosenzweig and J. V. Singh, "Organizational Environments and the Multinational Enterprise," The Academy of Management Review, vol. 16, no. 2, pp. 340-361, 1991.

[64] K. Hewett, M. S. Roth, and K. Roth, "Conditions influencing headquarters and foreign subsidiary roles in marketing activities and their effects on performance," Journal of International Business Studies, vol. 34, no. 6, pp. 567-585, 2003.

[65] J. T. Campbell, L. Eden, and S. R. Miller, "Multinationals and corporate social responsibility in host countries: Does distance matter?," Journal of International Business Studies, vol. 43, no. 1, pp. 84$106,2012$.

[66] G. Hofstede, G. J. Hofstede, and M. Minkov, Cultures and Organizations: Software of the Mind, Third Edition. McGraw-Hill Education, 2010.

[67] L. R. Gomez-Mejia and L. E. Palich, "Cultural Diversity and the Performance of Multinational Firms," Journal of International Business Studies, vol. 28, no. 2, pp. 309-335, 1997.

[68] J. Khuntia, A. Kathuria, M. G. Andrade-Rojas, T. Saldanha, and N. Celly, "How Foreign and Domestic Firms Differ in Leveraging IT-enabled Supply Chain Information Integration in BOP Markets: The Role of Supplier and Client Business Collaboration," Journal of the Association for Information Systems, vol. 22, no. 3, 2021.

[69] A. A. Tsay, J. V. Gray, I. J. Noh, and J. T. Mahoney, "A review of production and operations management research on outsourcing in supply chains: Implications for the theory of the firm," Production and Operations Management, vol. 27, no. 7, pp. 1177-1220, 2018.

[70] B. Jacobs and V. Singhal, "The effect of the Rana Plaza disaster on shareholder wealth of retailers: Implications for sourcing strategies and supply chain governance," Journal of Operations Management, vol. 49, 2017. 